\title{
Early bronchial inflammation and remodeling and airway hyperresponsiveness at school age
}

\section{Malmberg, Leo Pekka}

2020-07

Malmberg , L P , Malmström , K , Kotaniemi-Syrjänen , A , Lohi , J , Pelkonen , A S , Sarna , S \& Mäkelä , M J 2020 , ' Early bronchial inflammation and remodeling and airway hyperresponsiveness at school age ' , Allergy : European journal of allergy and clinical immunology , vol. 75 , no. 7 , pp. 1765-1768 . https://doi.org/10.1111/all.14198

http://hdl.handle.net/10138/326328

https://doi.org/10.1111/all.14198

acceptedVersion

Downloaded from Helda, University of Helsinki institutional repository.

This is an electronic reprint of the original article.

This reprint may differ from the original in pagination and typographic detail.

Please cite the original version. 
DR. LEO PEKKA MALMBERG (Orcid ID : 0000-0001-5087-1160)

Article type : Letter to the Editor

EARLY BRONCHIAL INFLAMMATION AND REMODELING AND AIRWAY HYPERRESPONSIVENESS AT SCHOOL AGE

L. Pekka Malmberg ${ }^{1}$, Kristiina Malmström ${ }^{1}$, Anne Kotaniemi-Syrjänen ${ }^{1}$, Jouko Lohi ${ }^{2}$, Anna S. Pelkonen ${ }^{1}$, Seppo Sarna ${ }^{4}$, Mika J. Mäkelä ${ }^{1}$

${ }^{1}$ Dept. of Allergy, Skin and Allergy Hospital, University of Helsinki and Helsinki University Hospital, Finland; '2Dept. of Pathology, University of Helsinki and Helsinki University Hospital, Finland; ${ }^{4}$ Dept. of Public Health, University of Helsinki Finland.

Corresponding author and reprint requests to: Dr. L. Pekka Malmberg, Skin and Allergy Hospital, Meilahdentie 2, PoBox 160, 00029 HUS, Helsinki, Finland.

Email: pekka.malmberg@hus.fi; Tel: +358947186217; Fax: +358947186280

This article has been accepted for publication and undergone full peer review but has not been through the copyediting, typesetting, pagination and proofreading process, which may lead to differences between this version and the Version of Record. Please cite this article as doi: 10.1111/ALL.14198

This article is protected by copyright. All rights reserved 
Longitudinal birth cohort studies and follow-up of wheezy infants suggest that airway hyperresponsiveness (AHR), a hallmark of asthma, is determined already in infancy $(1,2)$. It is not known whether such an early establishment of AHR is linked to early morphological alterations related to wheezing disorders. Airway remodeling is a characteristic feature of asthma, characterized by structural changes such as epithelial injury, thickening of reticular basement membrane (RBM) and increased airway smooth muscle (ASM) mass (3). In children with persistent wheeze, from the age of 1 year to school age, remodeling and inflammation develop in parallel (4-6). In this observational prospective study, we hypothesized that early airway inflammation or remodeling would be associated with persistent AHR later in life.

Details of the study population and methods are included in the online supplement. The original study population included 49 infants (median age 1.1 years) who were referred to a tertiary centre due to troublesome respiratory symptoms, and who underwent infant lung function tests and bronchoscopy as part of their clinical assessment. All infants were born full-term and had experienced at least one physician-diagnosed episode of wheezing.

The infants underwent whole-body plethysmography, and assessment of maximal flow at functional residual capacity (VmaxFRC) by using the rapid thoracoabdominal compression technique, and in a subgroup of infants, bronchial challenge test to methacholine.

In the bronchoscopy, endobronchial biopsies were taken from the main carina, and the specimens were analyzed for RBM thickness, the amount of ASM expressed as the percentage of cross-sectional area of the airway (ASM\%), and inflammatory cells by immunostaining.

At the median age of 7 years, the children were invited to a follow-up visit including a standardized questionnaire and lung function testing for airway responsiveness to methacholine and exercise. Approval for this study was obtained from Ethics Committee for Children's Hospital. A written informed consent was obtained from the guardians of the children. 
Lung function was measured using the oscillometric technique. An exercise challenge was performed as a standardized running test for 6-8 min. A dosimetric bronchial provocation test with methacholine was applied to determine the provocative dose causing an increase of $40 \%$ in respiratory resistance (PD40Rrs5) and the dose response slope (DRS).

Current asthma was defined as physician-diagnosed asthma ever and either intermittent or continuous anti-inflammatory treatment during the past year.

Altogether 39 of the original group of 49 children ( $80 \%$ ) participated in the follow-up visit and lung function data were obtained in 36 (Table 1). Physician-diagnosed asthma ever was present in 33 of 39 (85\%) children. Asthma was considered current in 15 (42\%) children.

AHR to methacholine in infancy (PD40VmaxFRC) was significantly associated with methacholine responsiveness at the follow-up (PD40Rrs5) ( $r=0.47 ; p=0.014)$ (Figure 1A). This relationship was highly significant expressed as DRS ( $p=0.55 ; p=0.005)$.

Thickness of RBM in infancy was not associated with lung function or AHR at the follow-up visit. There was a significant correlation between bronchial ASM\% in infancy and exercise-induced increase in Rrs5 at the follow-up ( $r=0.39 ; p=0.021$ ) (Figure 1B). Those children who responded significantly (increase of Rrs5 at least $40 \%$ after exercise) at the follow-up, had a higher median ASM\% (20.3 vs 10.6; $p=0.023$ ) and a higher number of bronchial mast cells in ASM (95.1 vs 38.9; $p=0.007$ ) in infancy. In addition, infant ASM\% had been higher in children with a history of hospitalization due to wheezing exacerbation ever than in those without such episodes (16.3 vs 9.6; $p=0.045)$.

The bronchial eosinophils were few but present in 17 of 39 infants. A weak association was found between the number of bronchial eosinophils and PD40Rrs5 at the follow-up ( $r=-0.34 ; p=0.046)$. In addition, those infants who presented bronchial eosinophils had more severe AHR to methacholine at the follow-up than those without eosinophils ( $p=0.035)$ (Figure 1C).

Supplementary data are included in the online version.

This article is protected by copyright. All rights reserved 
The results show the early establishment of AHR in children with wheeze. Here we also report for the first time, that subtle findings in airway inflammation and remodeling related to wheezing disorder associate with later persistence of airway responsiveness in childhood.

Caution should be exercised in generalizing the observed results, since the cohort constituted of a highly selected group of infants referred to a tertiary centre. As those subjects having macroscopic findings of structural anomalies were not included in the series, it is probable that most of the children represented early onset wheezing disorder of infancy. The high prevalence of asthma and AHR at the follow-up also indicate a selection bias. Ethical considerations hinder the inclusion of a healthy control group for bronchoscopic evaluation, and the associations were bound to be analyzed within the cohort, which is a clear limitation of the study.

Previously, we have reported findings from another cohort of infants with recurrent lower respiratory tract symptoms, who, despite reduced lung function, showed very little evidence of remodeling or eosinophilia in the carinal biopsies (4). In subsequent follow-up study, significant associations between RBM thickness and the density of bronchial mast cells with the amount of purchased inhaled corticosteroids at the age of 3 yrs were found (7). Increased ASM has been found in preschool wheezers who develop asthma at school age (8). Also experimental studies agree our findings on the relationship between ASM thickness and AHR (9).

Although bronchial eosinophils were few in infancy, we found a significant association between their presence and AHR to methacholine at the follow-up. Studies in severe preschool wheeze have shown eosinophilic inflammation consistent of asthma (5). The association between the number of mast cells in ASM and EIB at follow-up also supports the concept of inflammatory mechanisms in early establishment of AHR.

In conclusion, in a highly selected group of children with a history of early wheeze, ASM thickness and mast cell infiltration in infancy were associated with EIB and wheezing episodes requiring hospitalizations by school age, while bronchial eosinophils in infancy were associated with increased AHR to methacholine at school age. These preliminary findings suggest that inflammatory and structural mechanisms are involved in the early establishment of AHR in childhood.

This article is protected by copyright. All rights reserved 
Table 1. Characteristics and lung function of the children $(n=39)$ participating in the follow-up visit.

Male, $\mathrm{n}(\%)$

Age at the time of biopsy, median (range), yrs

FRC in infancy, median (IQR), z-score

sGaw in infancy, median (IQR), z-score

VmaxFRC in infancy, median (IQR), z-score

PD40VmaxFRC in infancy, median (IQR), $\mu \mathrm{g}$

Age at the time of biopsy, median (IQR), mo

Symptom duration at the time of biopsy, median (IQR), mo

Wheezing episodes by the time of biopsy, median (range), $n$

Follow-up characteristics

Age, median (range), yrs

Physician-diagnosed disease ever, n (\%)

Asthma

Atopic eczema

Rhinoconjunctivitis

Food allergy

Wheeze classification, $\mathrm{n}(\%)$

Viral wheeze

Multiple trigger wheeze

Persistent asthma symptoms during the last year, $n$ (\%)

Regular inhaled corticosteroids during the last year, $\mathrm{n}(\%)$

Systemic corticosteroids due to exacerbations

-during the last year, $\mathrm{n}(\%)$
$36(92)$

$1.3(0.5 ; 2.1)$

$0.3(-0.2 ; 1.9)$

$-2.6(-3.5 ; 0.2)$

$-1.5(-2.2 ;-0.5)$

$315(153 ; 888)^{\dagger}$

13.8 (7.2;17.9)

$8.0(5.0 ; 13.9)$

$2(1-11)$

$7.0(4.0 ; 9.8)$

$11(28)$

$3(8)$

$5(13)$

$29(74)$

$10(26)$

7 (18)

$12(31)$

$3(8)$

This article is protected by copyright. All rights reserved 
-ever, n (\%)

Hospitalizations due to exacerbations

-during the last year, $\mathrm{n}(\%)$

-ever, n (\%)

Parental smoking, n (\%)

Parental asthma, $\mathrm{n}(\%)$

Skin prick positivity, $\mathrm{n}(\%)$

Follow-up lung function

Rrs5, median (range), $\mathrm{kPal}^{-1} \mathrm{~s}$

$0.77(0.46 ; 1.49)$

Rrs5, median (range), z-score

$0.16(-2.41 ; 3.93)$

Xrs5, median (range), $\mathrm{kPal}^{-1} \mathrm{~s}$

$-0.23(-0.69 ;-0.14)$

Xrs5, median (range), z-score

$-0.78(-6.97 ; 0.81)$

Abnormal baseline lung function, $n(\%)$

$10(26)$

Exercise-induced increase in Rrs5, median (range)

$19.5(-2 ; 61)$

Exercise-induced increase in $\operatorname{Rrs} 5$ at least $40 \%, \mathrm{n}(\%)$

$4(10)$

PD40Rrs5 in methacholine challenge, median (IQR), $\mu \mathrm{g}$

$190(83 ; 469)$

PD40Rrs5 less than $400 \mu \mathrm{g}, \mathrm{n}(\%)$

$25(65)$

FENO, median (range), ppb

$6.8(3.0 ; 51.6)$

FRC=functional residual capacity; sGaw=specific airway conductance; VmaxFRC=maximal flow at FRC;

PD40VmaxFRC=provocative dose of methacholine producing a decrease of $40 \%$ in VmaxFRC;

IQR=interquartile range; ${ }^{\dagger} n=28 ;{ }^{\ddagger} n=37$; Rrs $5=$ respiratory resistance at $5 \mathrm{~Hz}$; $X r s 5=$ respiratory reactance at $5 \mathrm{~Hz}$; PD40Rrs5=provocative dose of methacholine producing an increase of $40 \%$ in Rrs5;

$I Q R=$ interquartile range; $F E N O=$ fractional concentration of exhaled nitric oxide.

This article is protected by copyright. All rights reserved 

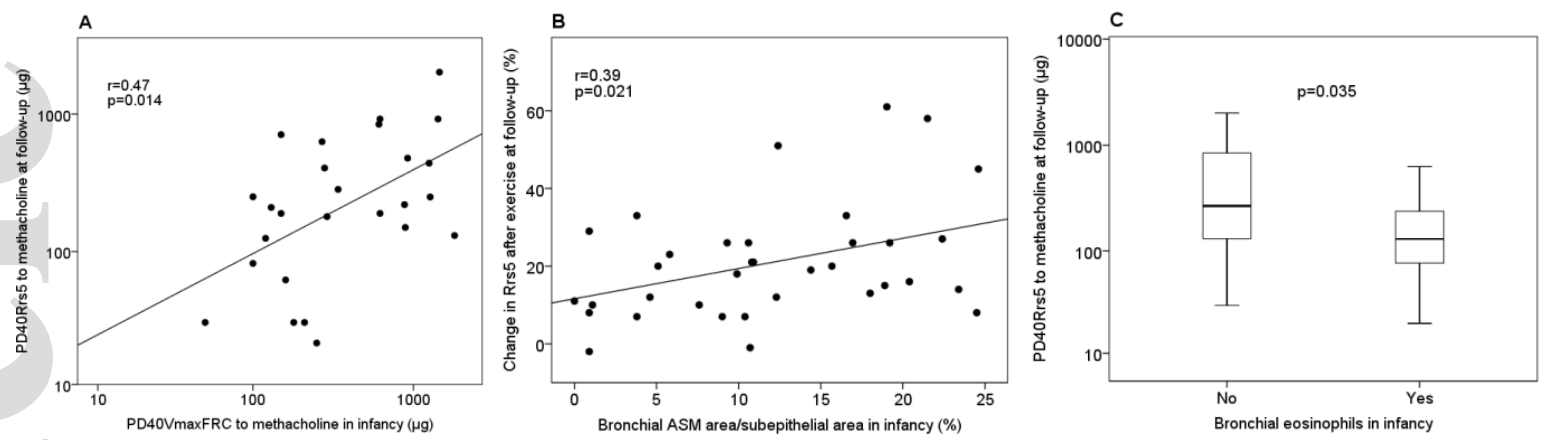

Figure 1. The association between (A) airway hyperresponsiveness in infancy (PD40VmaxFRC) and at the follow-up visit (PD40Rrs5), (B) the amount of airway smooth muscle (ASM) and the exercise induced change in respiratory resistance (Rrs5) in a running test at the follow-up visit, and $(C)$ the presence of bronchial eosinophils in infancy and airway hyperresponsiveness to methacholine (PD40Rrs5) at the follow-up visit. 


\section{REFERENCES}

1.

Turner SW, Young S, Goldblatt J, Landau LI, Le Souef PN. Childhood asthma and increased airway responsiveness. A relationship that begins in infancy. Am J Respir Crit Care Med. 2008;179:98-104. 2.

Delacourt C, Benoist MR, Waernessyckle S, Rufin P, Brouard JJ, de Blic J, et al. Relationship between bronchial responsiveness and clinical evolution in infants who wheeze. Am J Respir Crit Care Med. 2001;164:1382-6.

3. Saglani S, Lloyd CM. Novel concepts in airway inflammation and remodeling in asthma. Eur Resp J. 2015;46:1796-804.

4.

Saglani S, Malmstrom K, Pelkonen A, Malmberg LP, Lindahl H, Kajosaari M, et al. Airway remodeling and inflammation in symptomtic infants with reversible airflow obstruction. Am J Respir Crit Care Med. 2005;171:722-7.

5. Saglani S, Payne D, Zhu J, Wang Z, Nicholson AG, Bush A, et al. Early detection of airway wall remodeling and eosinophilic inflammation in preschool wheezers. Am J Respir Crit Care Med. 2007;176:858-64.

6. Castro-Rodriquez JA, Saglani S, Rodriguez-Martinez CE, Oyarzyn MA, Bush A. The relationship between inflammation and remodeling in childhood asthma: a systemtic review. Pediatr Pulmonol. 2018;53:824-35.

7. Malmström K, Pelkonen A, Malmberg LP, Sarna S, Lindahl H, Kajosaari M, et al. Lung function, airway remodelling and inflammation in symptomatic infants: outcome at 3 years. Thorax. 2011;66:157-62.

8. O'Reilly R, Ullman N, Irving S, Bossley CJ, Sonnappa S, Zhu J, et al. Increased airway smooth muscle in preschool wheezers who have asthma at school age. J Allergy Clin Immunol. 2013;131:1024-32. 9. Oliver MN, Fabry B, Marinkovic A, Mijailovich SM, Butler JP, Fredberg JL. Airway hyperresponsiveness, remodeling, amd smooth muscle mass. Am J Respir Cell Mol Biol. 2007;37:264-72.

This article is protected by copyright. All rights reserved 
Acknowledgements: The authors thank the research nurses Tuija Rito, Anssi Koivuselkä and Helena Punkari from Skin and Allergy Hospital, for their work with the infants and children during the study. The expertise of Dr Harry Lindahl for acquiring the infant bronchial biopsies is greatly appreciated. Pauli Lohi is acknowledged for expert help in quantification of ASM and RBM.

Conflicts of interest: The authors declare that they have no conflicts of interests relating the submitted work.

Author's contributions: LPM, KM, ASP and MJM conceived and designed the study; LPM, KM and AK-S acquired the lung function data; JL analyzed the biopsy data; HL acquired the biopsy data and interpreted macroscopic bronchoscopic findings; LPM, KM and SS collected and analyzed the statistical data; LPM and KM drafted the manuscript, which was critically edited and approved by all authors.

Sources of support: The Nummela Sanatorium Foundation, the Finnish Society of Allergy and Immunology, Sigrid Juselius Foundation, Pediatric Research Foundation and Helsinki University Hospital Research Funds

L. Pekka Malmberg ${ }^{1}$, Kristiina Malmström ${ }^{1}$, Anne Kotaniemi-Syrjänen ${ }^{1}$, Jouko Lohi ${ }^{2}$, Anna S. Pelkonen ${ }^{1}$, Seppo Sarna ${ }^{4}$, Mika J. Mäkelä ${ }^{1}$

${ }^{1}$ Dept. of Allergy, Skin and Allergy Hospital, University of Helsinki and Helsinki University Hospital, Finland; '2Dept. of Pathology, University of Helsinki and Helsinki University Hospital, Finland; ${ }^{4}$ Dept. of Public Health, University of Helsinki Finland.

Correspondence: Dr. L. Pekka Malmberg, Skin and Allergy Hospital, Meilahdentie 2, PoBox 160, 00029 HUS, Helsinki, Finland.

Email: pekka.malmberg@hus.fi; Tel: +358947186217; Fax: +358947186280 